\title{
Application of Rosemary (rosmarinus officinalis l.) Based Natural Antioxidant During Deep Fat Frying of Noodle
}

\author{
Navneet Singh Deora ${ }^{*}$, Aastha Deswal, Sanjith Madhavan
}

Nalanda Research and Development Center (N.R.D.C), Prasan Solutions Pvt. Limited, Cochin, Kerala, India A R T I C L E I N F O

A B S T R A C T

Article history:

Received 21 May 2015

Accepted 22 February 2016

Available online, ISSN: 2148-127X

Keywords.

Rosemary

Frying

Noodles

Antioxidant

Free fatty acid

* Corresponding Author:

E-mail: navneetsinghdeora@gmail.com
The aim of this study was to evaluate the effects of a natural antioxidant derived from rosemary extract on the stabilization of palmolein oil during deep-fat frying of Noodles. Palmolein oil with tertiary butylhydroquinone (TBHQ), a synthetic antioxidant and palmolein without antioxidant were used as positive controls. Thermo-oxidative transformation were measured according to various physical and chemical parameters. Total polar compounds (TPC), free fatty acids (FFA) were measured during the study. All the parameters evaluated in the study increased with the number of frying cycles. The order of effectiveness of antioxidants for inhibition of palmolein oil degradation in deepnoodles was: PRESOL (rosemary based extract) > TBHQ > Control. In terms of oil consumption, it was observed that noodles fried in oil with rosemary extract had lower value of oil consumption as compared to TBHQ and control. The TBHQ degradation kinetics was also evaluated with frying cycle. It showed an exponential decay with increase in frying cycles. Also samples containing natural antioxidant had a least changes in the colour as compared to TBHQ and control at the end of frying cycle.

\section{Introduction}

Over the past decade, fried noodles are gaining global popularity (Fu, 2008). It is a known fact that fats and oils in fried noodle are oxidized during processing, circulation and preservation. This reaction causes a deterioration in taste, flavour, odour, colour, texture and appearance, and a decrease in the nutritional value of the foods (Rho et al., 1986). The shelf life of fried noodles is also limited to around 4-5 months due to oxidative rancidity. Thus, controlling oxidation during frying of noodles is of paramount importance. Also a high level of oil absorption and calorie is a one of the primary concern of the instant fried noodles as its effects product cost and overall shelf life.

To prevent oxidation, the use of synthetic antioxidant is in practice from past many decades. Low-cost synthetic antioxidants are often used to slow down lipid oxidation, such as butylated hydroxytoluene (BHT), butylated hydroxyanisole (BHA) and tertiary butylhydroquinone (TBHQ). However, BHT and BHA have been reported to have toxic and carcinogenic effects (Frankel, 2014). Also, they are very effective during the storage and transport of oils and fats, but they are less effective at frying temperatures, due to their volatility. However, in the recent years, much of the interest has developed in naturally occurring antioxidants, because of the adverse attention received by the synthetic antioxidants, and because of the worldwide trend to avoid or minimize the use of artificial food additives (Filiz and Seydim, 2014; Gad and Sayd, 2015; Saral et al., 2014). Also the use of natural antioxidants for frying purposes has increased during the last few years (Bera et al., 2006; Budak et al., 2015; Riveros et al., 2015; Urbancic et al., 2014). Plant extracts, especially antioxidants obtained from herbs and spices, have been proposed for stabilizing frying oils.

Among natural antioxidant sources, rosemary (Rosmarinus officinalis L.), a woody aromatic herb that is native to the Mediterranean countries, has recently been authorized by the European Union under Directive 95/2/EC and assigned E-392 as its E number (European Union Directives 2010/67/EU and 2010/69/EU). Rosemary extracts provide an important source of natural antioxidants used commercially in foods. These extracts are particularly active as antioxidants at the high temperatures in frying fats. They protect the oils during frying and their antioxidant activity is carried over into the fried foods (Rho et al., 1986).

Thus the objective of this study is to carry out comparative analysis by incorporating natural antioxidant (rosemary based) PRESOL ${ }^{\mathrm{TM}}$ (brand name), THBQ (synthetic antioxidant), and control (without antioxidant) in the palmolin oil for frying instant noodles. 


\section{Material and Methods}

\section{Materials}

PRESOL $^{\mathrm{TM}}$ (Rosemary based extract), a product developed through patented process technology (Mooppil \& Francis, 2013) of Prasan solutions India pvt. Limited (Cochin, Kerela), was used in this present study. Amount of antioxidant added was 200 ppm for the present study. The contents of the major rosemary anti-oxidative components, carnosic acid, was $1.7 \%$. All of the chemicals for the analysis and the synthetic antioxidants was of analytical grade, and were purchased from Merck (Darmstadt, Germany). Refined wheat flour and salt was purchased from the local market. The palmolein oil without added antioxidant was purchased from the Parrisons Limited Company, Cochin.

\section{Noodle Preparation}

The trial methodology for the preparation and frying of noodle is presented in the Figure 1. The noodles were prepared using automatic noodle making machine (Company- Sohon, China; Model Number: SH-M3). After noodle extrusion, it was fried in the palmolein oil. A domestic deep-fat fryer with a 3-L-volume vessel was used for the deep-fat frying. Temperature was monitored with digital thermometers. For each deep-frying cycle, after heating the oil to $150^{\circ} \mathrm{C}$, extruded noodle $(100 \mathrm{~g}$ per batch) was added and deep fried for $45 \mathrm{sec}$. for a frying cycle. The frying temperature and time was decided as per as standard industry procedure (Hou, 2010). The use of 60 frying cycles was chosen as the endpoint because the best performing oil reached approximately $21-25 \%$ polar compounds at this stage, which is close to that of the standard for spoiled oils in various countries worldwide (Bastida and Sánchez-Muniz, 2002).

\section{Estimation of Free Fatty Acid}

Free fatty acid (FFA) content, of heated oil samples were determined as per (AOCS, 2003).

\section{Total Polar Content (TPC) Value Analysis}

The temperature of sample oils were maintained at 45 $50^{\circ} \mathrm{C}$ and TPC of samples were measured using a Testo ${ }^{\mathrm{TM}}$ 265 cooking oil tester according to the manufactures operation guide. Each sampling was done in triplicate and each experiment was repeated three times. The principles of Testo 265 cooking oil tester is to measure the changes of dielectric constant in the oil samples, the concentration of which is highly correlated with the concentration of total polar matter (Stier, 2004; Stier, 2013, Weisshaar, 2014).

\section{Determination of TBHQ in The Oil}

The TBHQ in the oil was analysed by the HPLC (Shimadzu LC) as per standard method (Kitada et al., 1984).

\section{Sensory Evaluation and Colour Analysis}

The fried noodles were subjected to sensory evaluation by semi trained panellist. Ten semi-trained panellists were chosen from among staffs of the Prasan solutions (India) Pvt. Ltd. (Larmond, 1977). All panellists regularly participated in sensory evaluation and are also regular consumers of fried noodles. Also the colour of the oil was analysed visually and digital photographs were taken for different batches for comparative analysis.

\section{Statistical Analysis}

Each analysis was carried out in triplicate. The Fisher's least significant difference procedure was used to determine the significant differences among the means of treatments, at $\mathrm{P}<0.05$. The data were analysed statistically by ANOVA and Duncan's multiple range test using commercially available software package SPSS software program (SPSS Inc., Chicago, IL).

\section{Result and Discussion}

\section{Effect of TPC during Deep Fat Frying}

Determination of polar compounds in used oils and fats is a well-accepted method due to its accuracy and reproducibility. It provides the most reliable measure of the extent of deterioration in frying oils and fats in most situations (Fritsch, 1981). The nonpolar fraction of the deteriorated oil and fats is made up of all unaltered triacylglycerol (Aladedunye and Przybylski, 2009). Total polar compounds are considered to be nonvolatile compounds that have a higher polarity than triacylglycerol as a result of thermal, hydrolytic and oxidative alteration. Consequently, the higher the amount of polar compounds in oil, the worse is its quality (Gharachorloo et al., 2010). Recommendations of the 3rd International Symposium on Deep-Fat Frying in 2000 have defined TPC Value less than $25 \%$ as criteria for the assessment of used frying oils and frying fats (Weisshaar, 2014).

The purpose of this method is to determine the level of polar oxidized components in an oil sample used for frying noodle. Faster rate of formation of polar components is cumulative indication of progressive degradation of oil. TPC was found to increase with the frying time for all the oils. The rate of increase was gradual for sample containing PRESOL as compared to TBHQ added samples at the end of the frying period. It can be seen that addition of natural antioxidant (PRESOL $^{\mathrm{TM}}$ ) effectively reduced the formation of polar compounds effectively as compared to TBHQ added oil sample. The PRESOL at $200 \mathrm{ppm}$ had least value of TPC $(13.9 \%)$ after $60^{\text {th }}$ batches of frying as compared to TBHQ (16.3\%) and control (21.6\%). The variation of TPC with frying cycle is presented in the Figure 2.

\section{Changes in Free Fatty Acid Content (FFA)}

The amount of FFA in fats and oils can be used to indicate the extent of its deterioration due to hydrolysis of triacylglycerol (TAG) and/or cleavage and oxidation of fatty acid double bonds. Free fatty acid (FFA) is an important fat quality indicator during each stage of fats and oils processing and is generally accepted as a regular quality parameter in noodle industry (Fu, 2008; Gotoh et 
al., 2007). The changes of FFA with frying cycle is presented in the Figure 3. As shown in Figure 3, there was a linear increase in the values of FFA with different frying cycles. Despite the inexistence of mandatory rejection points for used oil regarding hydrolysis (Paul et al., 1997), this parameter is mostly used in rapid commercial tests as an estimation of the rejection point. Based on the information obtained from these frying experiments, at the end of the frying cycle, the total change in FFA values from the initial to end of the frying cycle, the lowest were found to be in oil with natural antioxidant (PRESOL) and TBHQ and highest value was found in control oil samples. This data does indicate that the natural antioxidant could be used in case of synthetic antioxidant TBHQ for controlling the FFA of oil.
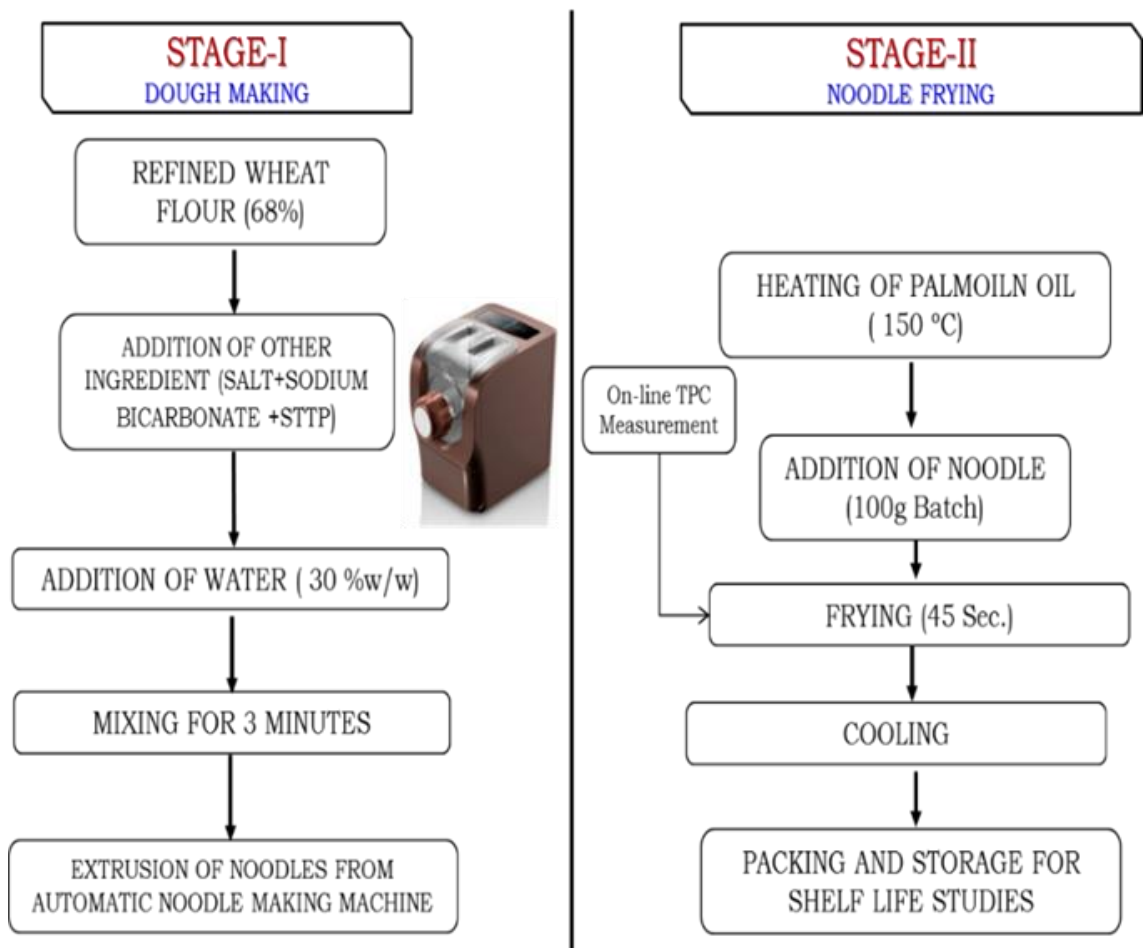

Figure 1 Trial Methodology for noodle making and frying

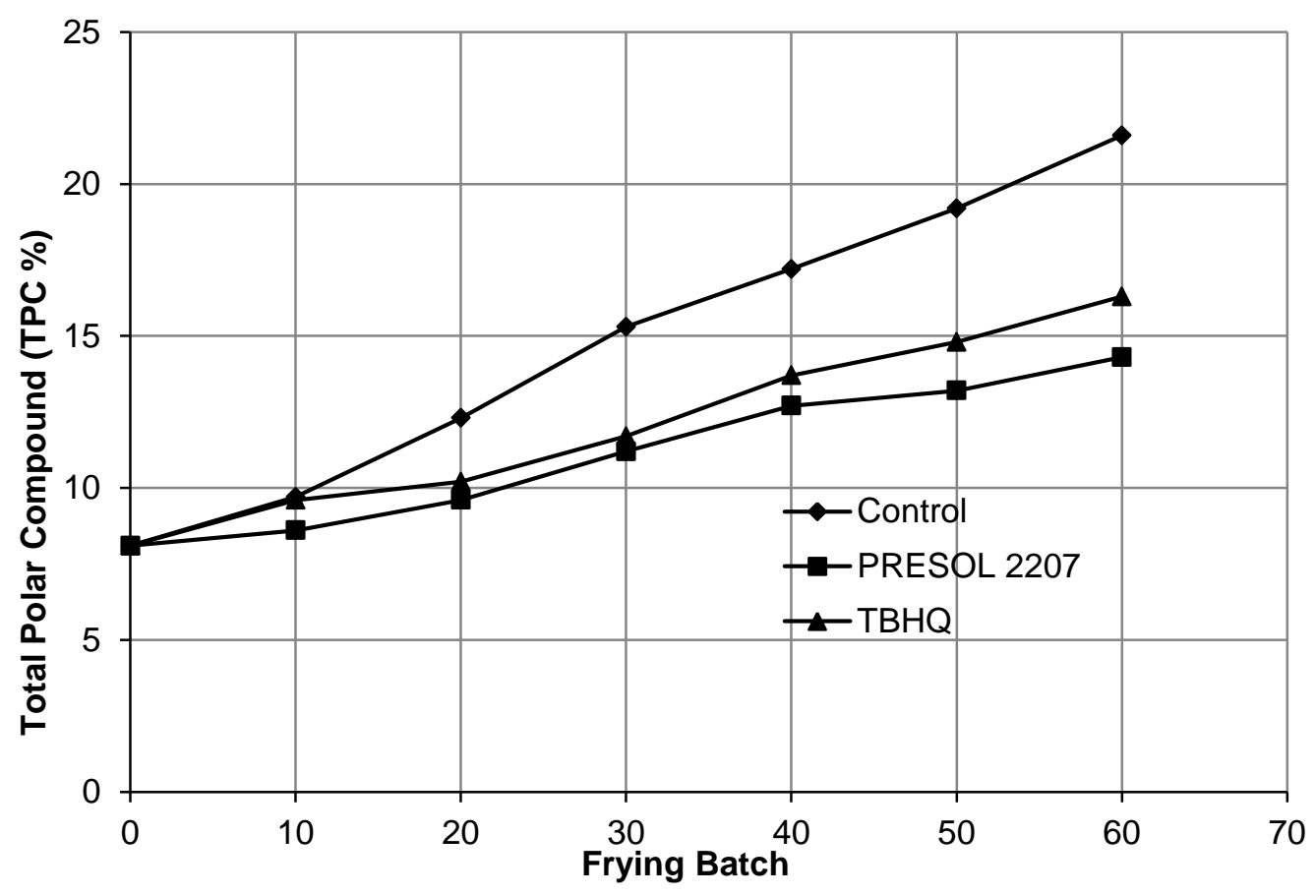

Figure 2 Changes of TPC with Different Frying batch 


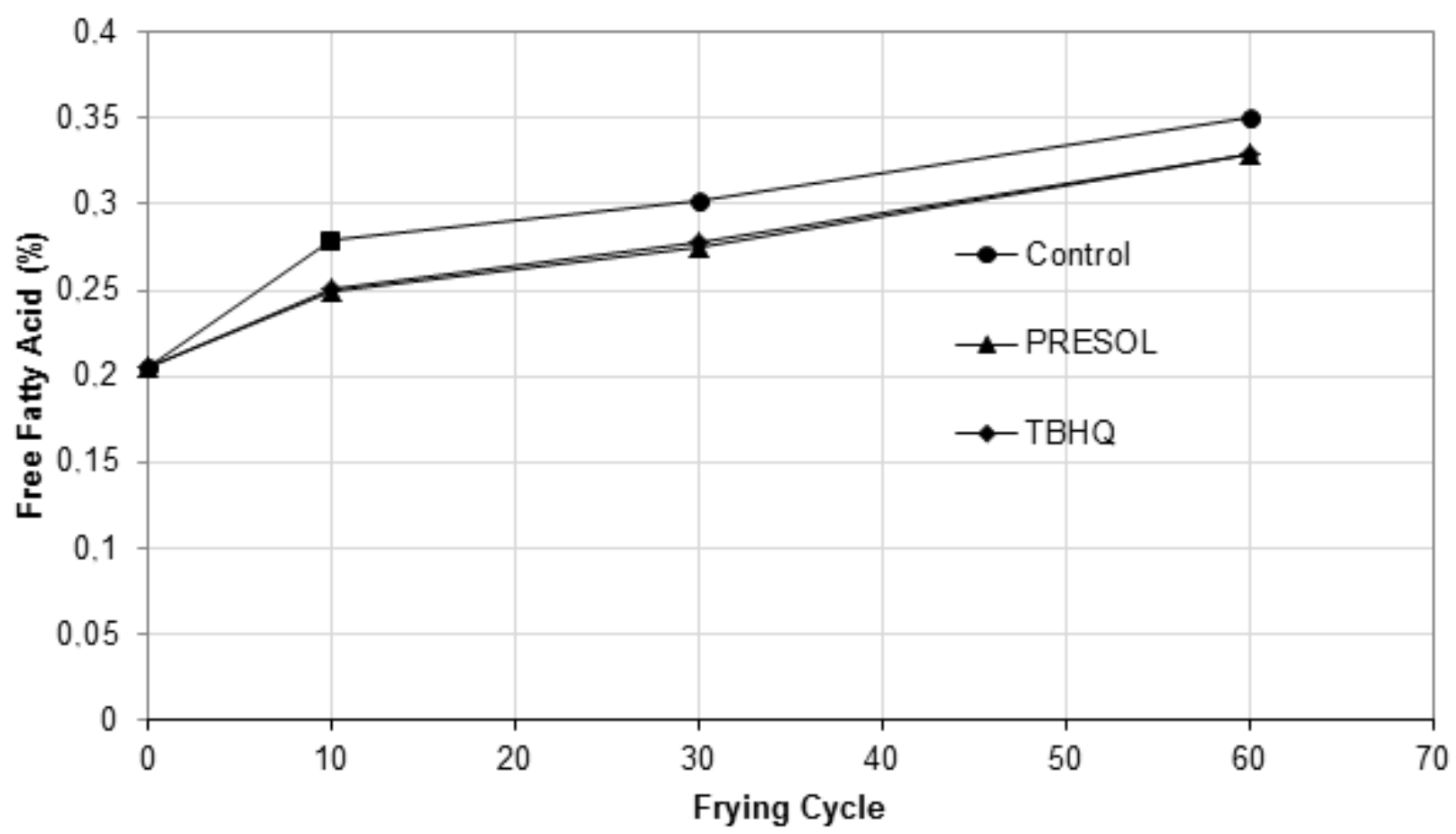

Figure 3 Changes of FFA with Different Frying batch

Table 1 Comparative analysis of Oil consumption

\begin{tabular}{l|ccc}
\multicolumn{1}{c|}{ Experimental design } & $\begin{array}{c}\text { Control(Kg Oil/Kg } \\
\text { fried Noodle })\end{array}$ & $\begin{array}{c}\text { PRESOL (Kg Oil/Kg } \\
\text { fried Noodle ) }\end{array}$ & $\begin{array}{c}\text { TBHQ (Kg Oil/Kg } \\
\text { fried Noodle ) }\end{array}$ \\
\hline Oil Level before Frying $\left(0^{\text {th }}\right.$ Batch) & 3.53 & 3.53 & 3.53 \\
Oil Remaining After Frying for $\left(60^{\text {th }}\right.$ Batch) & 2.01 & 2.155 & 2.075 \\
Total Oil Consumed (Kg.) & 1.52 & 1.375 & 1.455 \\
\hline
\end{tabular}

\section{Oil Consumptions}

The Table 1 shows the comparative analysis of oil consumption. Using PRESOL at 200 ppm gives a distinct advantage over TBHQ in terms of significant reduction in Oil consumption (Table 1). We can understand that the oil consumption $/ \mathrm{kg}$ of the fried noodle using PRESOL is comparatively less as compared to TBHQ and control. This observation gives a distinct advantage to the manufacture in terms cost saving by increasing the productivity of the fried noodles.

The reason for the lower oil consumption behaviour could be attributed to interfacial phenomenon. The interfacial phenomenon has also been reflected in past studies (Dana and Saguy, 2006; Gertz, 2014; Moreira and Barrufet, 1998). The materials which affect the heat transfer at the oil food interface must act to reduce the surface tension between the two immiscible materials. These materials act as and are referred to as surfactants. As the oil degrades, more surfactants are formed causing increased contact between the food and oil, excessive oil pickup by the food, and increased heat transfer to the surface of the food resulting in excessive drying and darkening of the surface. Consequently, the oil viscosity increases which increase the amount of oil on the food surface (Orthoefer et al., 2006). However, it could be assumed that due to lower value of TPC natural antioxidant PRESOL, there would be lesser amount of surfactants in the oil which might play a significant role in lower oil consumption as compared to TBHQ and control.

\section{Kinetics of TBHQ Degradation}

Synthetic antioxidants like TBHQ have been used extensively in deep-frying fats, because they provide protection when heating fats. It has been reported in past by many researcher that chemical degradation of antioxidants seems to be the major pathway for antioxidant loss at high temperatures. Volatilization and steam distillation due to the high temperature and the large amount of steam water escaping from the food have also been postulated to be the reason for chemical degradation (EFSA, 2004; Velasco et al., 2008). Moreover, it has also been found that effectiveness of antioxidants is reduced with number of frying (Mehta and Swinburn, 2001). In past it has been proposed that TBHQ degrades into Tert-butylbenzoquinone (TBBQ) as a primary oxidation product during frying (Mehta and Swinburn, 2001). 


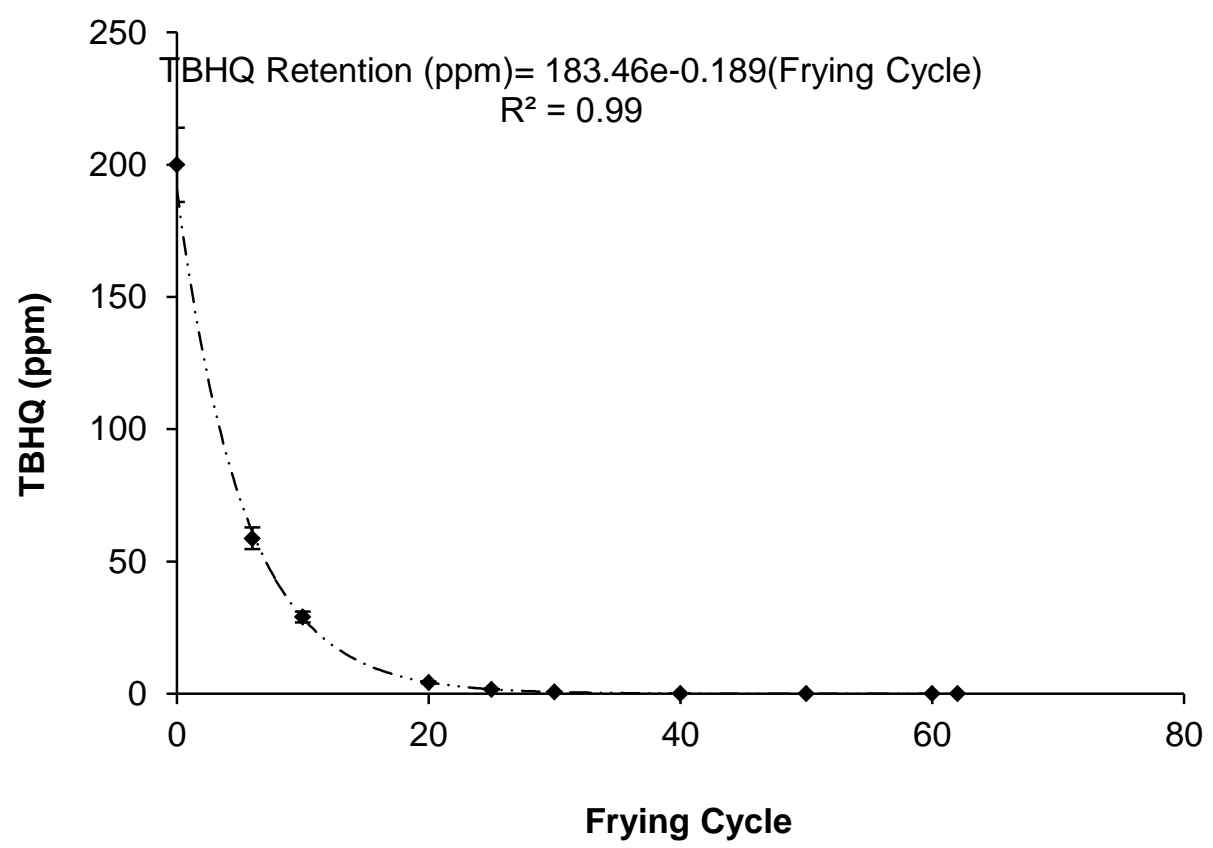

Figure 4 TBHQ degradation Kinetics

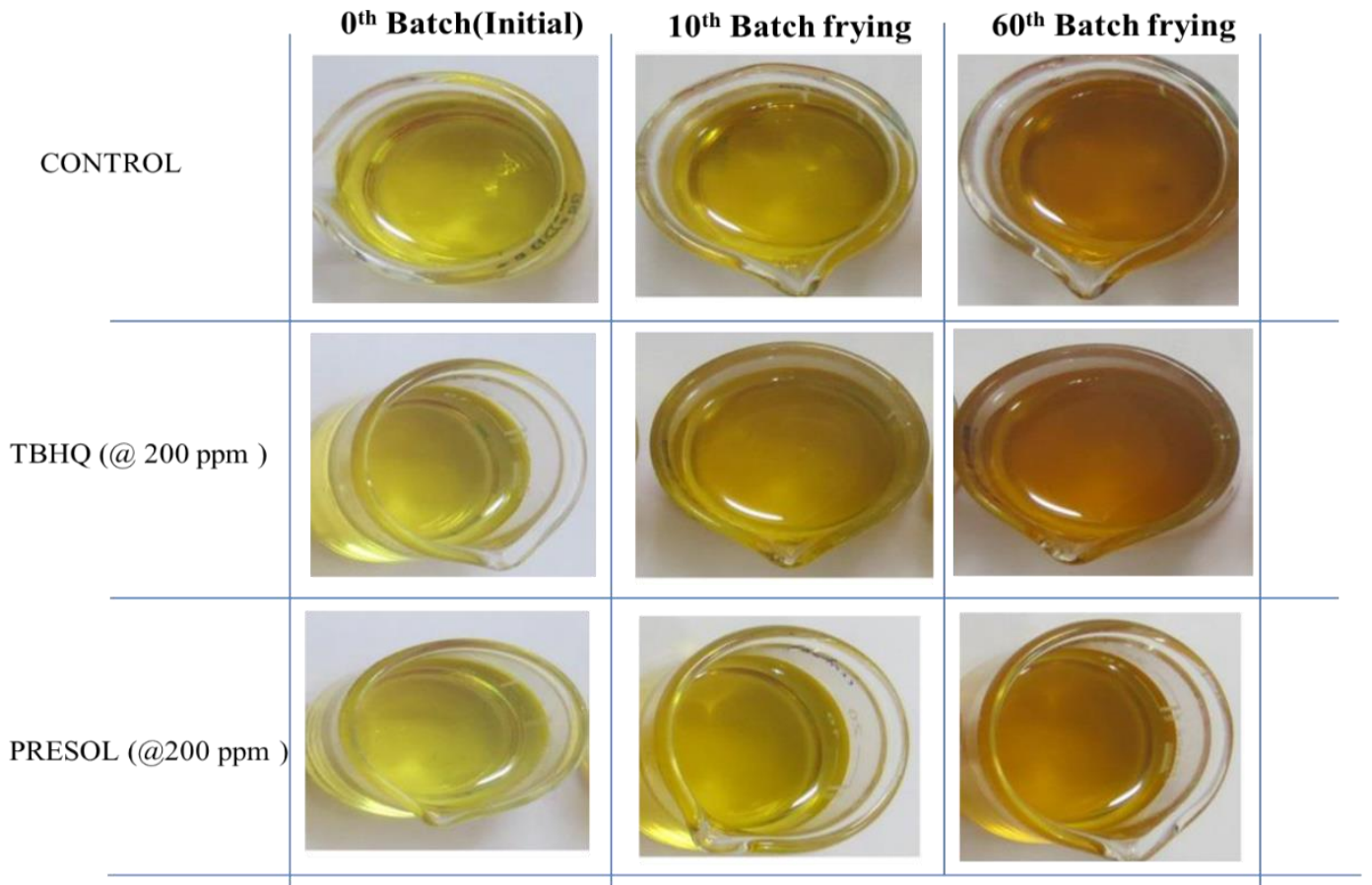

Figure 5 Comparative Analysis of color of Frying oil at different Frying Batch

Figure 4 shows the degradation kinetics of TBHQ during frying. An exponential trend was observed for TBHQ degradation. After $30^{\text {th }}$ batch of frying, the concentration of TBHQ was very limited. It could be due to conversion of TBHQ to its oxidation products. The reduced concentration of TBHQ might be the reason for the lower effectiveness during the end of frying cycle. Studies on the fate of synthetic antioxidant like TBHQ, BHA and BHT have been carried our extensively (Lin, Warner, \& Fazio, 1981; Warner, Daniels, Lin, Joe Jr, \& Fazio, 1986). It was found from these studies that TBHQ had the highest volatility during frying. The breakdown products of antioxidant compounds can have antioxidant properties (Kmiecik et al., 2015). Kim and Pratt (1990) identified and characterized the decomposition products of TBHQ heated at frying temperatures, including tertiary butylbenzoquinone (TBBQ) as the primary and major oxidation product of TBHQ. They reported that the interconversion between TBHQ and TBBQ played the greatest part in the antioxidant effectiveness and carrythrough effect of TBHQ. 
Sensory Evaluation and Colour Changes in Frying Oil

There were no significant changes in the fried noodles for all the samples used in the study by the sensory panellist. However, noticeable difference was observed in the colour of the oil as seen from the Figure 5. Colour has been widely used as one of the important parameter to understand an index of oil quality during deep fat frying. When foods are fried in heated oil, many complex chemical reactions occur resulting in the production of degradation products. As these reactions proceed, the functional, sensory and nutritional quality of the fat/oil changes and may eventually reach a point where it is no longer suitable for preparation of high quality fried products and the frying fat/oil will have to be discarded (Maskan, 2003; Paul and Mittal, 1996). The oil rapidly changes from a light yellow to an orange brown Colour during frying. This is the combined result of oxidation, polymerization and other chemical changes which also result in an increase in viscosity of the frying oil (Sánchez-Gimeno et al., 2008).

The comparative analysis of color of frying oil at different frying batch is presented in the Figure 5. As seen from the Figure 5, with increasing frying batches, the Colour of the oil degrades to brown-yellow as compared to initial batch oil. However, in case of natural antioxidant (PRESOL), one can visually notice that there is least degradation of Colour as compared to other samples. The changes in Colour and viscosity of frying oil are the signs of oil deterioration. In past many authors have reported high correlation between colour parameters and oil degradation during frying (Krokida et al., 2001; SánchezGimeno et al., 2008). The Colour may darken as heating or frying proceeds. This is mainly the result of oxidative reactions; highly coloured compounds being formed by a mechanism that is still not fully understood (Maskan, 2003). Thus on the basis of Colour also, one can see that PRESOL plays an effective role in reduced rate of change of Colour thereby indicating less sign of oil deterioration with frying cycle.

\section{Conclusion}

The present study has revealed that PRESOL $^{\mathrm{TM}}$, a rosemary extract based natural antioxidant formulation effectively slows palmolein oil deterioration during noodle frying. In terms of the TPCs, FFAs, our study shows that the oil treated with rosemary extract had lower values compared to the control oil and the oil with the addition of TBHQ. The rosemary extract showed considerable antioxidative effects at a much lower concentration of active ingredient compared to the synthetic products $(200 \mathrm{mg} / \mathrm{kg}$ active ingredient). Also there is a reduced amount of oil consumption using PRESOL as compared to TBHQ. Thus, it can be concluded that rosemary based natural antioxidant can be used to control the frying oil deterioration of fried noodles. However future work in terms of shelf life estimation need to be carried out.

\section{References}

Aladedunye FA, Przybylski R. 2009. Degradation and nutritional quality changes of oil during frying. J. Am. Oil Chem. Soc., 86: 149-156.

AOCS. 2003. Official methods and recommended practices of the AOCS. 5th edn, Champaign IL: AOCS press, methods, Ca 5a40, Cd 8-53,Ce 2-66, Cd 18-90 and Cd 11C-93.

Bastida S, Sánchez-Muniz FJ. 2002. Polar content vs. TAG oligomer content in the frying-life assessment of monounsaturated and polyunsaturated oils used in deep-frying. J. Am. Oil Chem. Soc., 79: 447-451. doi: 10.1007/s11746-0020504-8

Bera D, Lahiri D, Nag A. 2006. Studies on a natural antioxidant for stabilization of edible oil and comparison with synthetic antioxidants. J. Food Eng., 74: 542-545.

Budak NH, Ozçelik F, Güzel-Seydim ZB. 2015. Antioxidant Activity and Phenolic Content of Apple Cider. Turkish Journal of Agriculture-Food Science and Technology. 3.

Dana D, Saguy IS. 2006. Review: Mechanism of oil uptake during deep-fat frying and the surfactant effect-theory and myth. Adv. Colloid Interface Sci., 128-130: 267-272. doi: http://dx.doi.org/10.1016/j.cis.2006.11.013

EFSA. 2004. Opinion of the Scientific Panel on Food Additives, Flavourings, Processing Aids and Materials in Contact with Food on a request from the Commission related to tertiaryButylhydroquinone (TBHQ). The EFSA Journal: 1-50.

Filiz BE, Seydim AC. 2014. Antioxidant Properties of Some Dried Fruits. Turkish Journal of Agriculture-Food Science and Technology. 2.

Frankel EN. 2014. Lipid Oxidation., U.S.A: Elsevier. ISBN 9780857097927: Elsevier Science.

Fritsch CW. 1981. Measurements of frying fat deterioration: A brief review. Journal of the American Oil Chemists' Society. 58: 272-274. doi: 10.1007/bf02582355

Fu BX. 2008. Asian noodles: History, classification, raw materials, and processing. Food Res. Int., 41: 888-902.

Gad AS, Sayd AF. 2015. Antioxidant Properties of Rosemary and Its Potential Uses as Natural Antioxidant in Dairy Products-A Review. Food and Nutrition Sciences. 6: 179.

Gertz C. 2014. Fundamentals of the frying process. Eur. J. Lipid Sci. Technol., 116: 669-674. doi: 10.1002/ejlt.201400015

Gharachorloo M, Ghavami M, Mahdiani M, Azizinezhad R. 2010. The Effects of Microwave Frying on Physicochemical Properties of Frying and Sunflower Oils. J. Am. Oil Chem. Soc., 87: 355-360. doi: 10.1007/s11746-009-1508-y

Hou GG. 2010. Asian noodles: Science, technology, and processing. New Jersey: Wiley.

Kim C, Pratt D. 1990. Degradation Products of 2tertButylhydroquinone at Frying Temperature. J. Food Sci., 55: 847-847.

Kitada Y, Tamase K, Mizobuchi M, Sasaki M, Tanigawa K, Yamamoto M, Nakazawa H. 1984. Simplified determination of tert-butylhydroquinone in vegetable oils, butter, and margarine. Anal. Chem., 33: E33-E35.

Kmiecik D, Korczak J, Rudzińska M, Gramza-Michałowska A, Hęś M, Kobus-Cisowska J. 2015. Stabilisation of phytosterols by natural and synthetic antioxidants in high temperature conditions. Food Chem., 173: 966-971.

Krokida M, Oreopoulou V, Maroulis Z, Marinos-Kouris D. 2001. Colour changes during deep fat frying. J. Food Eng., 48: 219225.

Larmond E. 1977. Laboratory methods for sensory evaluation of food.

Lin F, Warner C, Fazio T. 1981. Alteration of phenolic antioxidants in heated vegetable oil. Journal of the American Oil Chemists' Society. 58: A789-A792.

Maskan M. 2003. Change in colour and rheological behaviour of sunflower seed oil during frying and after adsorbent treatment of used oil Eur. Food Res. Technol., 218: 20-25. 
Mehta U, Swinburn B. 2001. A review of factors affecting fat absorption in hot chips. Crit. Rev. Food Sci. Nutr., 41: 133-154.

Mooppil S, Francis P. 2013. Herbal extract composition and a process thereof. PCT/IB2013/056643. doi: https://www.google.com/patents/US20140248361

Moreira RG, Barrufet MA. 1998. A new approach to describe oil absorption in fried foods: a simulation study. J. Food Eng., 35: 1-22. doi: http://dx.doi.org/10.1016/S0260-8774(98)00020-X

Gotoh, Iwasawa, Watanabe, Osato \& Wada, 2007. Oxidation of fats and oils in instant noodles stored Under various conditions. Journal of Food Lipids 350-365.

Orthoefer F, List GR, Erickson M. 2006. Evaluation of used frying oil. In M. D. Erickson (Ed.), Deep frying: chemistry, nutrition, and practical applications (pp. 329-342).

Paul S, Mittal G. 1996. Dynamics of fat/oil degradation during frying based on optical properties. J. Food Eng., 30: 389-403.

Paul S, Mittal G, Chinnan M. 1997. Regulating the use of degraded oil/fat in deep fat/oil food frying. Crit. Rev. Food Sci. Nutr., 37: 635-662.

Rho K, Seib P, Chung O, Chung D. 1986. Retardation of rancidity in deep-fried instant noodles (ramyon). Journal of the American Oil Chemists' Society. 63: 251-256.

Riveros CG, Nepote V, Grosso NR. 2015. Thyme and basil essential oils included in edible coatings as a natural preserving method of oilseed kernels. J. Sci. Food Agric.
Sánchez-Gimeno A, Negueruela A, Benito M, Vercet A, Oria R. 2008. Some physical changes in Bajo Aragón extra virgin olive oil during the frying process. Food Chem., 110: 654-658.

Saral Ö, Ölmez Z, Şahin H. 2014. Comparison of Antioxidant Properties of Wild Blueberries (Vaccinium arctostaphylos L. and Vaccinium myrtillus L.) with Cultivated Blueberry Varieties (Vaccinium corymbosum L.) in Artvin Region of Turkey. Turkish Journal of Agriculture-Food Science and Technology. 3.

Stier RF. 2004. Tests to monitor quality of deep-frying fats and oils. Eur. J. Lipid Sci. Technol., 106: 766-771. doi: 10.1002/ejlt.200401049

Stier RF. 2013. Ensuring the health and safety of fried foods. Eur. J. Lipid Sci. Technol., 115: 956-964.

Urbancic S, Kolar MH, Dimitrijevic D, Demsar L, Vidrih R. 2014. Stabilisation of sunflower oil and reduction of acrylamide formation of potato with rosemary extract during deep-fat frying. LWT-Food Science and Technology. 57: 671-678.

Velasco J, Marmesat S, Dobarganes MC. 2008. Chemistry of Frying. Advances in deep-fat frying of foods: 33.

Warner CR, Daniels DH, Lin FS., Joe Jr, FL, Fazio T. 1986. Fate of antioxidants and antioxidant-derived products in deep-fat frying and cookie baking. J. Agric. Food Chem., 34: 1-5.

Weisshaar R. 2014. Quality control of used deep frying oils. Eur. J. Lipid Sci. Technol., 116: 716-722. doi: 10.1002/ejlt.201300269. 